\title{
Alelopatia de Camelina sativa Boiss. (Brassicaceae) sobre a germinação e desenvolvimento inicial de Bidens pilosa (L.) e Glycine max (L.) Merr.
}

\author{
Jéssica da Silva ${ }^{1}$ \\ Andréa Maria Teixeira Fortes ${ }^{2}$ \\ Fernanda Melo Gomes ${ }^{2}$ \\ Tassiane Terezinha Pinto ${ }^{3}$ \\ Thaliny Bonamigo 4 \\ Nayara Parisoto Boiago ${ }^{2}$ \\ ${ }^{1}$ Departamento de Biologia Aplicada à Agropecuária, Unesp - FCAV \\ Via de Acesso Prof. Paulo Donato Castellane, s/n, CEP 14884-900, Jaboticabal - SP, Brasil \\ ${ }^{2}$ Laboratório de Fisiologia Vegetal, Universidade Estadual do Oeste do Paraná, Cascavel - PR, Brasil \\ ${ }^{3}$ Departamento de Biologia, Universidade Federal de Santa Catarina, Florianópolis - SC, Brasil \\ ${ }^{4}$ Universidade Federal da Grande Dourados, Dourados - MS, Brasil \\ *Autor para correspondência \\ jeh_silva@hotmail.com
}

\section{Resumo}

Este estudo avaliou a possível presença de potencial alelopático na camelina, bem como o seu efeito sobre a germinação e o desenvolvimento inicial de plântulas de soja e picão-preto, a fim de verificar a possibilidade do cultivo dela com a soja no sistema de rotação de culturas e de seu uso como herbicida. Os experimentos foram realizados no Laboratório de Fisiologia Vegetal da Universidade Estadual do Oeste do Paraná, Cascavel, Paraná. O delineamento foi inteiramente casualizado e as avaliações realizadas diariamente. Os parâmetros avaliados foram: porcentagem de germinação, tempo e velocidade média de germinação e comprimento médio de raiz. Os dados obtidos foram submetidos ao Teste $\mathrm{F}$ e as médias comparadas pelo Teste de Tukey, em um nível de $5 \%$ de probabilidade. Os resultados comprovam a presença de potencial alelopático na camelina. Foi verificado que essa espécie pode ser considerada uma opção para o cultivo com a soja devido à interferência alelopática positiva provocada na cultura e por apresentar capacidade para utilização no controle de plantas invasoras como o picão-preto, tendo em vista que atrasou o desenvolvimento das plântulas testadas.

Palavras-chave: Ecofisiologia química, Extrato aquoso, Glucosinolatos

\section{Abstract}

Allelopathy of Camelina sativa Boiss. (Brassicaceae) on germination and early development of Bidens pilosa (L.) and Glycine max (L.) Merr. This study evaluated the possible presence of allelopathic potential in camelina, as well as its effect on germination and early growth of soybean seedlings and beggarticks, in order, to verify the possibility of cultivating it with soybeans in a culture rotation system and its use as a herbicide. 
The experiments were carried out at the Laboratory of Plant Physiology of Universidade Estadual do Oeste do Paraná, Cascavel, Paraná, Brazil. The design was completely randomized and the evaluations were held daily. The parameters under analysis were: germination percentage, time and average speed of germination, and average root lenght. The data obtained underwent the F-Test and the mean values were compared through Tukey's test, at a 5\% probability level. The results confirm the presence of allelopathic potential in camelina. It was found that this species can be considered an option for cultivating with soybean, due to the positive allelophatic interference caused in the culture and because it can be used in the control of weeds such as beggartick, having in mind that that it has delayed the development of the seedlings tested.

Key words: Aqueous extract, Chemical ecophysiology, Glucosinolates

\section{Introdução}

O termo alelopatia, do grego allelon $=$ de um para o outro, pathós $=$ sofrer, é utilizado para definir a interação química que ocorre entre organismos, a partir da liberação de substâncias oriundas do metabolismo secundários das plantas, os denominados aleloquímicos. Segundo a IAS (2010), este processo pode ser definido como os estudos que envolvem quaisquer processos com metabólitos secundários, sendo estes produzidos por plantas, algas, bactérias ou fungos, podendo influenciar o crescimento e desenvolvimento da produção agrícola e dos sistemas biológicos.

A liberação desses compostos secundários se dá através de processos como a exsudação radicular, lixiviação das folhas, volatilização de compostos e decomposição de resíduos, sendo os aleloquímicos comumente utilizados como alternativa ao uso de herbicidas, inseticidas e defensivos agrícolas (BORELLA; PASTORINI, 2009).

O crescente desejo de diminuir o uso de insumos químicos sintéticos nos agroecossistemas faz dos estudos ligados a alelopatia, uma ferramenta para melhoria da sustentabilidade dos sistemas de produção e da conservação da vegetação natural, pois representam uma alternativa biológica com ação específica e menos prejudicial ao meio ambiente (TUR et al., 2010).

Muitas espécies da família Brassicaceae são conhecidas por serem potencialmente alelopáticas. As espécies desta família sintetizam grandes quantidades de um metabólito secundário denominado glucosinolato, pertencente a um grupo de glicosídeos e são armazenados nos vacúolos celulares dos vegetais desta família (NEVES, 2005). Quando as células da planta são rompidas, os glucosinolatos ali presentes são hidrolisados, pela enzima mirosinase, originando compostos como isotiocianatos, com propriedades antibióticas (CHOESIN; BOERNER, 1991), tiocianatos, nitrilas e indóis, os quais são conhecidos como potentes substâncias alelopáticas e como eficientes biocidas (NEVES, 2005).

Dentre a família botânica Brassicaceae, a canola é uma espécie com grande destaque, não só por sua produção de óleo, mas também por seu efeito alelopático perante outras espécies (NEVES, 2005; MORAES, 2009). Também da família, e com efeito alelopático comprovado, há o nabo-forrageiro (Raphanus sativus L. var oleiferus) (TOKURA; NOBREGA, 2006; MORAES, 2009), a nabiça (Raphanus raphanistrum L.) (WANDSCHEER; PASTORINI, 2008) e a mostarda-preta (Brassica nigra (L.) Kock) (TAWAHA; TURK, 2003).

A Camelina sativa Boiss. é uma brassicácea oleaginosa popularmente conhecida como falso-linho ou ouro-do-prazer (CROWLEY, 1999). É uma cultura de primavera, com ciclo anual e que varia entre 90 a 100 dias, contudo, por apresentar-se bastante resistente ao frio depois de germinada pode ser considerada espécie de outono-inverno (WYSOCKI; SIROVATKA, 2010).

Nos últimos anos, a procura por esta planta cresceu principalmente nos Estados Unidos devido a sua peculiar composição, a qual apresenta elementos muito importantes à nutrição humana. É composta por cerca de $90 \%$ de ácidos graxos poliinsaturados ditos como nutricionalmente essenciais como o ácido linolêico (Omega 6) e o ácido alfa-linolênico (Omega 3) os quais constituem mais de $50 \%$ do óleo da camelina, sendo o ácido linolêico o predominante, constituindo de $35-40 \%$ do óleo total (LU, 2008).

Diante da busca mundial por combustíveis com baixa emissão de poluentes e de baixo custo de 
produção, o interesse pelo cultivo da C. sativa aumenta. Estudos realizados afirmam que esta espécie é uma ótima opção de produção de baixo custo, uma vez que, quando comparado ao cultivo de colza (Brassica napus L.), apresentou menor necessidade de aplicação de fertilizantes e pesticidas, gerando assim, economia ao produtor (CROWLEY, 1995; JOHNSON et al., 2009).

Assim, considerando a importância desta planta, o trabalho objetivou avaliar o possível potencial alelopático da C. sativa sob uma espécie bioindicadora e o efeito dos extratos aquosos de suas folhas frescas sobre a germinação e o desenvolvimento inicial da soja (Glycine max L. Merr), bem como seu possível potencial herbicida sobre o picão-preto (Bidens pilosa L.).

\section{Material e Métodos}

Os experimentos foram conduzidos no ano de 2010, no Laboratório de Fisiologia Vegetal da Universidade Estadual do Oeste do Paraná, Campus Cascavel.

O material consistiu em rolos de papel do tipo Germitest e placas de Petri com papel filtro, cada qual com três camadas, e foi previamente esterilizado em autoclave a $121^{\circ} \mathrm{C}$ por $20 \mathrm{~min}$ (BORTOLINI; FORTES, 2005). As sementes de alface (Lactuca sativa L.) e soja foram dispostas sobre o papel por serem fotoblásticas positivas, já as de picão-preto foram distribuídas sob o papel pelo fato de serem fotoblásticas negativas.

As placas de Petri foram umedecidas com $5 \mathrm{~mL}$ de extrato para a alface e $7 \mathrm{~mL}$ para o picão-preto. Os rolos de papel Germitest foram umedecidos com 2,5 vezes seu peso seco para o volume de solução. O material foi armazenado em câmara de germinação com fotoperíodo de $12 \mathrm{~h}$ e temperatura controlada de $25^{\circ} \mathrm{C}$.

Antes da montagem e avaliações, as mãos, bancadas e materiais utilizados passaram por procedimento de desinfecção, através da utilização de fungicida e bactericida, ambos a 10\% de concentração. As sementes de picão-preto e soja foram previamente tratadas com hipoclorito de sódio a $10 \%$ de concentração para descontaminação das mesmas.

As avaliações foram diárias, iniciando no dia seguinte a semeadura, sendo considerada como semente germinada aquela que apresentar no mínimo $2 \mathrm{~mm}$ de radícula (HADAS, 1976). Foi também verificado o comprimento de raiz primária de 5 plântulas por repetição no último dia de avaliação.

O delineamento experimental foi inteiramente casualisado. Foram analisados os parâmetros de porcentagem de germinação (PG), tempo médio de germinação (TMG), velocidade média de germinação (VMG) e comprimento médio de raiz primária (CMR), sendo as análises quanto ao tempo médio de germinação calculadas segundo Edmond e Drapalha (1958) e as da velocidade média de germinação, segundo Laboriau (1983).

Os dados para porcentagem de germinação foram submetidos à transformação do arco seno da raiz quadrada da porcentagem. Todos os parâmetros foram submetidos a análise de variância (teste F), sendo as médias comparadas pelo teste de Tukey a $5 \%$ de probabilidade.

\section{Resultados e Discussão}

De acordo com a Tabela 1, o extrato aquoso de C. sativa apresenta potencial alelopático, com efeito inibitório sobre a germinação e o comprimento médio de raiz da alface, principalmente a partir do extrato a $40 \%$ de concentração, sendo que, quanto maior a concentração do extrato, maior o efeito exercido. Foi observado também, efeito alelopático negativo em relação ao tempo médio de germinação das sementes, contudo, apenas no tratamento com extrato bruto.

Analisando os dados referentes à porcentagem de germinação, nota-se que o extrato não só apresentou comportamento inibitório, como também levou a redução de aproximadamente $100 \%$ na germinação da alface (Lactuca sativa L.) no tratamento com extrato bruto, quando comparado à testemunha.

No parâmetro comprimento médio de raiz, foi observada acentuada redução quando comparados os tratamentos à testemunha. Caso o mesmo efeito fosse observado em campo ou em espécies localizadas próximas a C. sativa, isso poderia ser prejudicial ao desenvolvimento das plântulas, uma vez que as raízes são responsáveis pela manutenção das funções vitais da planta, como absorção 
de nutrientes e água, comprometendo assim a produção final (KERBAUY, 2008).

TABELA 1: Porcentagem de germinação (PG), tempo (TMG) e velocidade média de germinação (VMG) e comprimento médio de raiz (CMR) de plântulas de alface submetidas ao extrato aquoso de folhas de Camelina. Cascavel-PR/2011.

\begin{tabular}{ccccc}
\hline $\begin{array}{c}\text { Concentração } \\
\text { do Extrato }\end{array}$ & $\begin{array}{c}{ }^{\mathbf{P} G} \\
\mathbf{( \% )}\end{array}$ & $\begin{array}{c}{ }^{1} \text { TMG } \\
\text { (dias) }\end{array}$ & $\begin{array}{c}{ }^{\mathbf{} V M G} \\
\text { (sementes/ } \\
\text { dia) }\end{array}$ & $\begin{array}{c}{ }^{1} \mathbf{C M R} \\
\text { (cm) }\end{array}$ \\
\hline Testemunha & $73 \mathrm{a}$ & $1,29 \mathrm{ab}$ & $0,79 \mathrm{a}$ & $1,69 \mathrm{a}$ \\
$\mathbf{2 0 \%}$ & $55 \mathrm{a}$ & $1,74 \mathrm{a}$ & $0,59 \mathrm{a}$ & $1,12 \mathrm{~b}$ \\
$\mathbf{4 0 \%}$ & $26 \mathrm{~b}$ & $1,69 \mathrm{a}$ & $0,59 \mathrm{a}$ & $0,41 \mathrm{c}$ \\
$\mathbf{6 0 \%}$ & $23 \mathrm{~b}$ & $1,83 \mathrm{a}$ & $0,56 \mathrm{a}$ & $0,22 \mathrm{~cd}$ \\
$\mathbf{8 0 \%}$ & $16 \mathrm{bc}$ & $1,97 \mathrm{a}$ & $0,59 \mathrm{a}$ & $0,26 \mathrm{~cd}$ \\
$\mathbf{1 0 0 \%}$ & $3 \mathrm{c}$ & $0,75 \mathrm{~b}$ & $0,75 \mathrm{a}$ & $0,15 \mathrm{~d}$ \\
\hline C.V. $(\%)$ & 19,97 & 27,01 & 38,46 & 13,94 \\
\hline
\end{tabular}

${ }^{1}$ Médias seguidas da mesma letra não diferem estatisticamente entre si, a 5\% de significância. C.V. - Coeficiente de variação.

Para o experimento de verificação da presença de potencial alelopático na camelina, foi escolhida a alface, uma espécie bioindicadora, e para tanto, deve apresentar germinação uniforme e rápida e um alto grau de sensibilidade aos metabólitos secundários, sendo os efeitos expressos mesmo em baixas concentrações (FERREIRA; AQUILA, 2000).

Os resultados obtidos no presente trabalho assemelham-se aos de outros autores que testaram também espécies da família Brassicacea, como Almeida (1991), que testou a influência dos extratos aquosos do nabo-forrageiro (Raphanus sativus L.) e da colza (Brassica napus L.) sobre a germinação e o comprimento de radícula de espécies silvestres e verificou, que ambos reduziram os parâmetros analisados, chegando em alguns casos, a anular a germinação de algumas espécies.

Os dados encontrados corroboram também com os de Rufato (2004) que constatou que as variáveis obtidas nas plantas sob tratamento com nabo-forrageiro foram menores do que as obtidas na testemunha e nos tratamentos com tremoço-azul (Lupinus angustifolius L.). Também são semelhantes aos encontrados por Rufato et al. (2006) que testaram a influência alelopática do nabo-forrageiro sobre o diâmetro do tronco, volume da copa, produção e fertilidade de plantas de pessegueiro e verificaram a interferência negativa no volume da copa das plantas.

Resultados análogos a estes foram encontrados em testes com outra espécie da família, a nabiça (Raphanus raphanistrum L.), realizados por Wandscheer e Pastorini (2008), onde foi observada redução da porcentagem e velocidade de germinação e comprimento radicular de plântulas de alface e tomate (Solanum lycopersicon L.).

A redução na porcentagem de germinação e no comprimento das radículas das plantas testadas sob efeito dos extratos de $C$. sativa pode ser resultante da decomposição dos glucosinolatos dos vacúolos celulares a isotiocianatos e tiocianatos, os quais afetam a germinação das sementes, uma vez que se apresentando em baixas concentrações atrasam o processo germinativo, mas mantém as sementes viáveis, porém, quando em altas concentrações podem penetrar em grandes quantidades nas sementes, reagindo com as enzimas de maneira irreversível, tornando assim as sementes inviáveis (PETERSEN et al., 2001).

Com relação à espécie invasora, picão-preto, observando a Tabela 2 verifica-se que o extrato aquoso de folhas de C. sativa tem efeito alelopático positivo, visto que houve alteração linear dos parâmetros tempo e velocidade média de germinação conforme aumento da concentração do extrato, o que em campo pode significar um possível controle do desenvolvimento das plântulas da espécie invasora.

Esse aumento no tempo médio de germinação e a consequente redução da velocidade da mesma apresentam-se como fator positivo para a área cultivada, pois, a velocidade sendo menor e o tempo maior, a germinação das sementes sofre atraso, podendo muitas vezes levar ao não desenvolvimento satisfatório das plantas, o que torna o controle químico exercido pelos compostos alelopáticos uma opção ecologicamente correta de controle de plantas invasoras, uma vez que assim não há necessidade de utilização de herbicidas sintéticos, diminuindo os impactos sobre o meio ambiente e para o ser humano, causados pelo uso de compostos sintéticos na agricultura (INOUE et al., 2010).

A porcentagem de germinação de picão-preto sob influência do extrato de canola, descrita por Neves 
(2005) difere da analisada no presente trabalho, uma vez que essa não foi alterada, porém, essas diferenças podem ser devido às diferentes condições climáticas em que as plantas foram coletadas e armazenadas, pois, apesar de pertencerem à mesma família, a concentração dos aleloquímicos nas plantas pode ser afetada por fatores ambientais, como temperatura e fertilidade do solo (EBERLEIN et al., 1998).

TABELA 2: Porcentagem de germinação (PG), tempo (TMG) e velocidade média de germinação (VMG) e comprimento médio de raiz (CMR) de plântulas de picão-preto submetidas ao extrato aquoso de camelina. Cascavel-PR/2011.

\begin{tabular}{ccccc}
\hline $\begin{array}{c}\text { Concentração } \\
\text { do Extrato }\end{array}$ & $\begin{array}{c}{ }^{1} \mathrm{PG} \\
\mathbf{( \% )}\end{array}$ & $\begin{array}{c}\text { 'TMG } \\
\text { (sementes/ } \\
\text { dia) }\end{array}$ & $\begin{array}{c}{ }^{\mathbf{1}} \text { VMG } \\
\text { (dias) }\end{array}$ & $\begin{array}{c}{ }^{1} \mathrm{CMR} \\
\text { (cm) }\end{array}$ \\
\hline Testemunha & $98 \mathrm{a}$ & $2,97 \mathrm{c}$ & $0,33 \mathrm{a}$ & $2,02 \mathrm{a}$ \\
$\mathbf{2 0 \%}$ & $96 \mathrm{a}$ & $3,48 \mathrm{bc}$ & $0,29 \mathrm{ab}$ & $2,33 \mathrm{a}$ \\
$\mathbf{4 0 \%}$ & $95 \mathrm{a}$ & $3,87 \mathrm{bc}$ & $0,27 \mathrm{abc}$ & $1,95 \mathrm{a}$ \\
$\mathbf{6 0 \%}$ & $99 \mathrm{a}$ & $4,30 \mathrm{ab}$ & $0,23 \mathrm{bc}$ & $2,15 \mathrm{a}$ \\
$\mathbf{8 0 \%}$ & $98 \mathrm{a}$ & $4,16 \mathrm{ab}$ & $0,24 \mathrm{bc}$ & $2,33 \mathrm{a}$ \\
$\mathbf{1 0 0 \%}$ & $89 \mathrm{a}$ & $5,07 \mathrm{a}$ & $0,19 \mathrm{c}$ & $2,32 \mathrm{a}$ \\
\hline C.V. $(\%)$ & 11,56 & 11,74 & 13,17 & 20,58 \\
\hline
\end{tabular}

${ }^{1}$ Médias seguidas da mesma letra não diferem estatisticamente entre si, a 5\% de significância. C.V. - Coeficiente de Variação.

Os resultados obtidos no presente trabalho quando comparados aos de Almeida (1991) que testou os extratos aquosos de colza e nabo-forrageiro sobre a germinação de picão-preto, diferem quanto à porcentagem de germinação, devido a esta não ter sofrido alteração neste experimento, contudo, quando comparadas às velocidades médias de germinação, os dados obtidos são semelhantes, pois, em ambos os casos a velocidade é reduzida conforme aumento da concentração do extrato.

Em experimento testando a influência de coberturas vegetais como nabo-forrageiro e colza, Tokura e Nóbrega (2006), observaram controle do desenvolvimento das plantas infestantes, o que se deve provavelmente à liberação de aleloquímicos durante a deterioração dessas plantas na área testada.

As alterações no tempo e velocidade média de germinação das sementes de picão-preto sob influência alelopática da camelina observadas neste estudo, podem ser decorrentes de mudanças nas funções fisiológicas das plantas, como fotossíntese, respiração e absorção de íons, as quais resultam diretamente em diferenças visíveis no desenvolvimento vegetal, conforme sugerido por Pires e Oliveira (2001).

Os resultados obtidos para a soja, segundo a Tabela 3, demonstram que o extrato aquoso de folhas de camelina exerceu efeito positivo na germinação e no comprimento médio de raiz das plântulas de soja.

O aumento da germinação, observado nos tratamentos com o extrato aquoso de folhas de camelina, pode ser devido ao incremento dos aleloquímicos desta às sementes, visto que a absorção dessas substâncias pode auxiliar na regulação das etapas do processo germinativo, as quais poderiam ser prejudicadas por fatores ambientais ou mesmo genéticos.

TABELA 3: Porcentagem de germinação (PG), tempo (TMG) e velocidade média de germinação (VMG) e comprimento médio de raiz (CMR) de plântulas de soja submetidas ao extrato aquoso de folhas de camelina. Cascavel-Pr/2011.

\begin{tabular}{ccccc}
\hline $\begin{array}{c}\text { Concentração } \\
\text { do Extrato }\end{array}$ & ${ }^{1} \mathbf{P G}$ & $\begin{array}{c}{ }^{1} \text { TMG } \\
\text { (sementes/ } \\
\text { dia) }\end{array}$ & $\begin{array}{c}{ }^{1} \text { VMG } \\
\text { (dias) }\end{array}$ & $\begin{array}{c}{ }^{1} \mathbf{C M R} \\
\text { (cm) }\end{array}$ \\
\hline $\begin{array}{c}\text { Testemunha } \\
\mathbf{2 0 \%}\end{array}$ & $79,0 \mathrm{~b}$ & $1,85 \mathrm{a}$ & $0,56 \mathrm{a}$ & $6,77 \mathrm{~b}$ \\
$\mathbf{4 0 \%}$ & $88,5 \mathrm{a}$ & $1,94 \mathrm{a}$ & $0,52 \mathrm{a}$ & $10,74 \mathrm{ab}$ \\
$\mathbf{6 0 \%}$ & $93,5 \mathrm{a}$ & $2,10 \mathrm{a}$ & $0,53 \mathrm{a}$ & $11,53 \mathrm{ab}$ \\
$\mathbf{8 0 \%}$ & $93,5 \mathrm{a}$ & $2,02 \mathrm{a}$ & $0,49 \mathrm{a}$ & $12,41 \mathrm{a}$ \\
$\mathbf{1 0 0 \%}$ & $91,5 \mathrm{ab}$ & $2,16 \mathrm{a}$ & $0,46 \mathrm{a}$ & $9,62 \mathrm{ab}$ \\
\hline C.V. (\%) & 7,47 & 9,85 & 13,14 & 23,35 \\
\hline
\end{tabular}

${ }^{1}$ Médias seguidas da mesma letra não diferem estatisticamente entre si, a 5\% de significância. C.V. - Coeficiente de Variação.

Analisando com maior atenção o parâmetro comprimento médio de raiz, observa-se que as médias obtidas nos tratamentos com extrato podem chegar a quase o dobro do obtido na testemunha, o que é benéfico ao vegetal, pois, sendo a raiz bem desenvolvida, ela pode apresentar um uso mais eficiente dos recursos disponíveis no solo, responder de maneira satisfatória a condições adversas à planta, como ventos fortes $\mathrm{e}$ deficiências hídricas e ainda auxiliar na manutenção 
das condições do solo, através da descompactação do mesmo (BAPTISTA et al., 2003). Esse aumento de comprimento pode ser derivado de um possível efeito inibitório que os aleloquímicos presentes no extrato das folhas de C. sativa tiveram sob o desenvolvimento das raízes secundárias das plântulas, mobilizando as reservas disponíveis apenas para o crescimento das raízes primárias, diferente da testemunha que mobilizou essas reservas também para as demais raízes.

Dados semelhantes aos obtidos no parâmetro comprimento médio de raiz foram observados em experimento realizado por Tokura e Nóbrega (2002), que testaram a influência de coberturas vegetais sobre a germinação e desenvolvimento inicial da soja e verificaram que o nabo-forrageiro e a colza afetam positivamente o comprimento radicular das plântulas de soja, bem como as médias de massa seca, porém, a germinação não sofreu alteração significativa.

Neves (2005), buscando analisar também o efeito alelopático das Brassicaceae, trabalhou com a palhada da canola, testando a influência desta sobre a germinação de sementes de soja em casa de vegetação e verificou que a germinação das sementes sofreu redução conforme aumento do extrato de canola. A velocidade média de emergência de radícula das plântulas foi afetada também, apresentando redução média de $31 \%$, sendo assim, ambos os resultados diferem dos apresentados do presente trabalho, uma vez que a camelina influenciou a germinação de forma positiva e não alterou significativamente a velocidade média de germinação, contudo deve-se considerar que os experimentos relativos a este trabalho foram realizados em laboratório, logo, as sementes foram induzidas a condições diferentes de germinação e desenvolvimento e até mesmo a efeitos diferentes dos mesmos aleloquímicos, devido às diferentes condições ambientes.

Testando os possíveis efeitos alelopáticos da cultura de canola sobre a produtividade, número de legumes e grãos por planta de soja, Motta et al. (2007) constataram que a canola interferiu de forma negativa nos parâmetros analisados, o que foi atribuído pela presença de potentes aleloquímicos na canola. Contudo, apesar de observar redução da produção final, os autores indicam um intervalo de 15 a 20 dias entre uma semeadura e outra, pois assim, os efeitos causados pela cultura anterior podem ser reduzidos. Esse período indicado entre a colheita e semeadura das culturas, deve-se provavelmente ao comportamento fitotóxico dos glucosinolatos encontrados na canola, quando hidrolisados, como já mencionado.

Segundo Calegari (2008), o uso do nabo-forrageiro antecedendo o milho no inverno em rotação com a soja, gerou rendimento superior das culturas, tanto em plantio direto como em convencional. Portanto, sendo o nabo e a camelina, espécies da mesma família, recomendase que esses estudos sejam realizados também com a camelina, pois ela pode contribuir para o cultivo assim como o nabo forrageiro quando utilizada no sistema de rotação de culturas.

Porém, em experimento realizado por Nóbrega et al. (2009), avaliando o efeito do nabo-forrageiro como cobertura vegetal, obteve-se redução na velocidade e porcentagem de emergência das plântulas de soja, resultados estes diferentes dos obtidos com a camelina nesse trabalho.

Em virtude dos resultados obtidos e da comparação deles com os trabalhos acima citados, entende-se que a camelina não afeta a germinação e o desenvolvimento da soja, sendo assim, pode ser considerada como alternativa para uso no sistema de rotação de culturas.

A partir dos resultados:

1) confirma-se o potencial alelopático de camelina, nas condições realizadas neste experimento.

2) O extrato aquoso das folhas de camelina apresenta potencial alelopático quando administrado à soja, e exerceu influência positiva em sua germinação e desenvolvimento, tornando-se uma opção de cultivo rotacionado com a cultura.

3) Quando administrado ao picão-preto, mostrou atividade inibitória, sendo essa representada pelo atraso na germinação das sementes, portanto, a camelina pode ser indicada como opção de controle de plantas invasoras. 


\section{Referências}

ALMEIDA, F. S. Efeitos alelopáticos de resíduos vegetais. Pesquisa Agropecuária Brasileira, Brasília, v. 26, n. 2, p. 221236, 1991.

BAPTISTA, J. Z.; FAHL, J. I.; FAZUOLI, L. Z. Avaliação do sistema radicular e a relação parte aérea e sistema radicular em progênies de Icatu. Revista Científica Eletrônica de Agronomia, ano 2, 3. ed., 2003. Disponível em: < http://www.revista.inf.br/ agro03/artigos/artigo03.pdf $>$.

BORELLA, J.; PASTORINI, L. H. Influência alelopática de Phytolacca dioica L. na germinação e crescimento inicial de tomate e picão-preto. Biotemas, Florianópolis, v. 22, n. 3, p. 67-75, 2009.

BORTOLINI, M. F.; FORTES, A. M. T. Efeitos alelopáticos sobre a germinação de sementes de soja (Glycine max L. Merrill). Semina: Ciências Agrárias, Londrina, v. 26, n. 1, p. 5-10, 2005.

CHOESIN, D. N.; BOERNER, R. E. J. Allyl isothiocyanate release and the allelopathic potential of Brassica napus (Brassicaceae). American Journal of Botany, Saint Louis, v. 78, p. 1083-1090, 1991.

CALEGARI, A. Plantas de cobertura e rotação de culturas no sistema plantio direto. Informações Agronômicas, Piracicaba, $\mathrm{n}$ 122, p. 18-21, 2008.

CROWLEY, J. K. Agronomy of Camelina sativa. EU Research Contract no AIR3-CT 94 2178, 1995.

CROWLEY, J. G. Evaluation of Camelina sativa as an alternative oilseed crop. Dublin: The Science of Farming and Food, 1999. p. 1-11.

EBERLEIN, C. V.; MORRA, M. J.; GUTTIERI, M. J.; BROWN, P. D.; BROWN, J. Glucosinolate production by five field-grown Brassica napus cultivars used as green manures. Weed Technology, Washington, v. 12, n. 4, p. 712-718, 1998.

EDMOND, J. B.; DRAPALHA, W. J. The effects of temperature, sand, soil, and acetone on germination of okra seeds. American Society for Horticultural Science, Itahaca, v. 71, p. 428-434, 1958.

FERREIRA. G. A.; AQUILA, M. E. A. Alelopatia: uma área emergente na ecofisiologia. Revista Brasileira de Fisiologia Vegetal, Campinas, v. 12, p. 175-204, 2000.

HADAS, A. Water uptake and germination of leguminous seeds under changing external water potential in osmotic solution. Journal of Experimental Botany, Oxford, v. 27, n. 3, p. 480-489, 1976.

IAS. INTERNATIONAL ALLELOPATHY SOCIETY Constitution and Bylaws. 2010. Disponível em $<\mathrm{http}$ ://www-ias. uca.es/bylaws.htm\#SECTION >. Acesso em: 05 junho 2010.

INOUE, M. H.; SANTANA, D. C.; SOUZA FILHO, A. P. S.; POSSAMAI, A. C. S.; SILVA, L. E.; PEREIRA, M. J. B.; PEREIRA, K. M. Potencial alelopático de Annona crassiflora: Efeitos sobre plantas daninhas. Planta Daninha, Viçosa, v. 28, n. 3, p. 489-498, 2010.

JOHNSON, J.; ENJALBERT, N.; SCHNEEKLOTH, J.; HELM, A.; MALHOTRA, R.; COONROD, D. Development of oilseed crops for biodiesel production under Colorado limited irrigation conditions. Completion Report, Boulder, n. 211, p. 1-49, 2009.

KERBAUY, G. B. Fisiologia Vegetal. Rio de Janeiro: Guanabara Koogan S.A., 2008. 431 p.
LABORIAU, L. G. A. A germinação de sementes. Washington: Organização Dos Estados Americanos, 1983. 172 p.

LU, C. Camelina sativa: a potencial oilseed crop for biofuels and genetically engineered products. Blacksburg: ISB New Reports, 2008. Disponível em: <http://www.isb.vt.edu/articles/jan0803. htm>.

MORAES, P. V. D. Alelopatia de espécies de cobertura na inibição de plantas daninhas na cultura do milho. Revista Brasileira de Agroecologia, Porto Alegre, v. 4, n. 3, p. 117, 2009.

MOTTA, M.; CIOTTI, R.; GAVIRAGHI, F.; MARTINS, J. A. K.; WAGNER, J. F.; VALENTINI, A. P. F.; ZAMBONATO, F.; CARBONERA, R.; SILVA, J. A. G. Efeito alelopático de canola (Brassica napus) no desenvolvimento e produção final de soja (Glycine max). In: CONGRESSO DE INICIAÇÃO CIENTÍFICA, XIX, 2007, Pelotas. Anais... Pelotas: UFPel, 2007. Versão eletrônica.

NEVES, R. Potencial alelopático da cultura de canola (Brassica napus L. var. oleifera) na supressão de picão-preto (Bidens sp.) e soja. 2005. 77 f. Dissertação (Mestrado em Produção Vegetal) Universidade de Passo Fundo, Passo Fundo, 2005. Disponível em: $<$ www.upf.br/ppgagro/download/ronaldoneves.pdf $>$.

NÓBREGA, L. H. P.; LIMA, G. P.; MARTINS, G. I.; MENEGHETTI, A. M. Germinação de sementes e crescimento de plântulas de soja (Glycine max L. Merrill) sob cobertura vegetal. Acta Scientiarum Agronomy, Maringá, v. 31, n. 3, p. 461-465, 2009

PETERSEN, J.; BELZ, R.; WALKER, F.; HURLE, K. Weet supression by release of isothiocyanates from turnip-rap mulch. Agronomy Journal, Madison, v. 93, p. 37-43, 2001.

PIRES, N. M.; OLIVEIRA, R. V. Alelopatia. In: OLIVEIRA, R. S.; CONSTANTIN, J. (Ed.). Plantas daninhas e seu manejo. Guaíba: Agropecuária, 2001. p. 145-187.

RUFATO, L. Influência da cobertura vegetal no desenvolvimento vegetativo de plantas de pessegueiro e na evolução da população de fitonematóides de solo. 2004. 101 f. Tese (Doutorado em Agronomia) - Universidade Federal de Pelotas, Pelotas, 2004.

RUFATO, L; ROSSI, A.; PICOLOTTO, L.; FACHINELLO, J. C. Plantas de cobertura de solo em pomar de pessegueiro (Prunus persica $\mathrm{L}$. Batsch) conduzido no sistema de produção integrada. Ciência Rural, Santa Maria, v. 36, n. 3, p. 814-821, 2006.

TAWAHA, A. M.; TURK, M. A. Allelopathic effects of black mustard (Brassica nigra) on germination and growth of wild barley (Hordeum spontaneum). Journal of Agronomy and Crop Science, Braunschweig, v. 189, n. 5, p. 298-303, 2003.

TOKURA, L. K.; NÓBREGA, L. H. P. Potencial alelopático de coberturas de inverno no desenvolvimento de plântulas de soja. Revista Varia Scientia, Cascavel, v. 02, n. 2, p. 19-26, 2002.

TOKURA, L. K.; NÓBREGA, L. H. P. Alelopatia de cultivos de cobertura vegetal sobre plantas infestantes. Acta Scientiarum Agronomy, Maringá, v. 28, n. 3, p. 378-384, 2006.

TUR, C. M.; BORELLA, J.; PASTORINI, L. H. Alelopatia de extratos aquosos de Duranta repens sobre a germinação e crescimento inicial de Lactuca sativa e Lycopersicum esculentum. Biotemas, Florianópolis, n. 23, v. 2, p. 13-22, 2010.

WANDSCHEER, A. C. D.; PASTORINI, L. H. Interferência alelopática de Raphanus raphanistrum L. sobre a germinação de Lactuca sativa L. e Solanum lycopersicon L. Ciência Rural, Santa Maria, v. 38, n. 4, p. 949-953, 2008. 
WYSOCKI, D.; SIROVATKA, N. Camelina, a potencial oilseed crop for semiarid Oregon. Disponível em: <http:// www.extension.oregonstate.edu/catalog/html/sr/sr1083... / sr1083 09.pdf>. Acesso em: 7 jun. 2010. 